\title{
It's right under our nose: homage to the Nobel Prize and other stories!
}

\author{
Stephen B Hanauer
}

After glancing at the index of the December 8 2005 issue of the New England Journal of Medicine (volume 353, number 23) I made the mistake of putting the issue to one side. I had recognized that a study of infliximab for the treatment of ulcerative colitis, of which I was an author, was published in that issue and had left the journal with my secretary to add the publication details to my CV. Now, having read the issue, I am impressed that its impact goes beyond the publication of the relevant original articles on Clostridium difficile-associated diarrhea and anti-tumor necrosis factor therapy for ulcerative colitis.

The issue includes a series of four articles in the 'Perspective' section, which, in my view, should be required reading for every medical student. The first article covers the discovery of Helicobacter pylori by Barry Marshall and Robin Warren, who had just received the Nobel Prize for their work. The other three articles focus on Robert Koch, Sir Arthur Conan Doyle, and medical writer Berton Roueché.

What these articles reveal is that, in an era of genetic and molecular medicine, there is still a role for clinical observation and description. Koch has been quoted as saying that "During my wandering through medicine, I encountered sites where gold was lying around. It needs a lot of serendipity to distinguish gold from ignobility; this however is not a particular achievement." I disagree, and prefer Louis Pasteur's belief that chance favors only the prepared mind.

\section{It is reassuring \\ that ... the \\ power of \\ clinical \\ observations \\ and deductive \\ reasoning \\ .... can lead \\ to research \\ deserving of a \\ Nobel Prize}

SB Hanauer is Editorin-Chief of Nature Clinical Practice Gastroenterology \& Hepatology.

\section{Competing interests}

The author declared he has no competing interests.

www.nature.com/clinicalpractice doi:10.1038/ncpgasthep0524
As gastroenterology fellows, we reviewed every gastric biopsy with an expert gastrointestinal pathologist. We weren't prepared and never recognized the spirochete organisms associated with gastritis and ulcers. By contrast, Marshall and Warren were prepared - the above article describes not only their observational abilities, but the background efforts they undertook to ward off the 'acid mafia' and the subtle, or not, disincentives of the pharmaceutical industry with regard to identifying an infectious cause (and potential cure) of ulcer disease. Similarly, there are Koch's powers of observation and deduction regarding anthrax and, to a lesser degree, tuberculosis, which highlight a wonderful similarity to the reasoning of Conan Doyle's detective, Sherlock Holmes. Indeed, these articles describe the traits of discovery derived from clinical observations in the setting of preparation, persistence, deductive reasoning and confirmation.

Furthermore, observations might not be sufficient to 'sell' a discovery. The article describing the medical writer Roueché complements a commentary on "The use of stories in clinical research and health policy" (JAMA [2005] 294; 2901). These narratives (stories) add 'meaning' to clinical observations that help us to understand the human consequences of diseases or discoveries.

It is reassuring that, in an era of genomics, proteomics, and molecular techniques, the power of clinical observations and deductive reasoning not only makes good 'stories', but can also lead to research deserving of a Nobel Prize. 